Article

\title{
Determining the Load Inertia Contribution from Different Power Consumer Groups
}

\author{
Henning Thiesen * and Clemens Jauch $(\mathbb{D}$ \\ Wind Energy Technology Institute (WETI), Flensburg University of Applied Sciences, \\ 24943 Flensburg, Germany; clemens.jauch@hs-flensburg.de \\ * Correspondence: henning.thiesen@hs-flensburg.de
}

Received: 27 February 2020; Accepted: 25 March 2020 ; Published: 1 April 2020

check for updates

\begin{abstract}
Power system inertia is a vital part of power system stability. The inertia response within the first seconds after a power imbalance reduces the velocity of which the grid frequency changes. At present, large shares of power system inertia are provided by synchronously rotating masses of conventional power plants. A minor part of power system inertia is supplied by power consumers. The energy system transformation results in an overall decreasing amount of power system inertia. Hence, inertia has to be provided synthetically in future power systems. In depth knowledge about the amount of inertia provided by power consumers is very important for a future application of units supplying synthetic inertia. It strongly promotes the technical efficiency and cost effective application. A blackout in the city of Flensburg allows for a detailed research on the inertia contribution from power consumers. Therefore, power consumer categories are introduced and the inertia contribution is calculated for each category. Overall, the inertia constant for different power consumers is in the range of 0.09 to $4.24 \mathrm{~s}$ if inertia constant calculations are based on the power demand. If inertia constant calculations are based on the apparent generator power, the load inertia constant is in the range of 0.01 to $0.19 \mathrm{~s}$.
\end{abstract}

Keywords: grid frequency stability; load inertia; power consumer groups; power system inertia; power system stability

\section{Introduction}

The most important challenge for global society is the challenge of mitigating the effects of the anthropogenic climate change. On 12 December 2015 political leaders of the world adopted the "Paris Agreement" which entered into force on 4 November 2016 [1]. The agreement's goal is to keep the global average temperature increase well below $1.5^{\circ} \mathrm{C}$ above pre-industrial levels [1]. Compared to the measures taken in previous years, efforts have to be increased significantly in order to accomplish the $1.5^{\circ} \mathrm{C}$ goal. Therefore, the power generation mix changes in many power systems to reduce $\mathrm{CO}_{2}$ emissions [2]. Previously, the power generation mix was primarily based on fully controllable $\mathrm{CO}_{2}$ emitting power plants [2]. Efforts will be directed to a power generation mix based on renewable energy sources, mainly volatile sources like Wind Turbines (WT) and Photovoltaic Systems (PV) [2]. For instance, in 1990 the share of Renewable Energy Sources (RES) (Hydro Power, Pumped Hydro Power, Geothermal, Solar, Wind, Tide, Wave, and Ocean) of the gross electricity generation was $12.79 \%$ in the European Community [3]. In 2007 when the European Community became the European Union, the share already increased up $14.68 \%$ and resulted in $27.98 \%$ in 2018 [3]. The share of gross electricity generation from WT and PV increased from $0.03 \%$ in 1990 up to $3.23 \%$ in 2007 and finally up to $15.37 \%$ in 2018 [3].

Along with an increasing demand for electricity, the increasing penetration of RES challenge power system operators, power markets and authorities [2,4]. Controllability of low inertia power 
systems and how to cope with a decreasing number of synchronously connected rotating masses in power systems is currently researched [2,5-8].

Power system inertia is an essential part in power system stability and its relevance and functionality has been described comprehensively by Tielens and Van Hertem in [2] and will be briefly introduced by the following paragraph: synchronised rotating masses determine the rate with which the grid frequency changes, commonly know as the Rate of Change of Frequency (ROCOF). In the event of a power imbalance, synchronised rotating masses absorb or release kinetic energy and exchange it with the power system in the form of electric energy. Hence, the speed with which the grid frequency changes decreases with higher power system inertia. Power units participating in active grid frequency control are not able to adapt their power output instantaneously. A certain amount of time is needed to change their power feed-in. This time is provided by the inertia response of rotating masses and the reduction of the ROCOF. State of the art WT and PV are connected to the power system via frequency converters. Thus, the moment of inertia of the rotating generation unit, if existent as in the case of a WT, is hidden to the power system. Power generation and energy storage units connected to the grid via frequency converters are able to emulate the power feed-in behaviour of a synchronous rotating mass in the event of a power imbalance [2,7-11].

In total, inertia is not only provided by power generation and storage units, power consumers participate in passive grid frequency control via an inertia response as well [12,13]. As of today, power system inertia is a by-product from synchronously rotating masses [2,8]. In future power systems, inertia will become a valuable good and has to be deployed intentionally [8]. To employ technologies providing either a natural synchronous or synthetic inertia response most efficiently and cost-effective, precise knowledge about the amount of inertia provided by power consumers is essential.

Different methods to determine the amount of inertia in a power system have been presented [14-16]. Inoue et al. applied a polynomial approximation to estimate the inertia constant [14]. Applying the method to ten different events in the $60 \mathrm{~Hz}$ area of the Japanese power system, resulted in inertia constants in the range of 7 to $9 \mathrm{~s}$ [14]. Chassin et al. applied the same method as presented in [14] considering the damping coefficient $K \Delta f$ to be neglectable during early onset of the event [15]. Overall, 388 plant outages in the Western Electricity Coordination Council were obtained of which 167 have been analysed [15]. Most of the time, the inertia constant was in the range of 3.5-7.5 s [15]. A simulative approach applying the swing equation for inertia constant estimation is presented in [16]. Wall et al. conlude their research with a median error of $1.56 \%$ with an inter-qartile range of $6.6 \%$ for inertia estimations for a variety of disturbance types and noise conditions [16]. A method to estimate load inertia in power systems with a high share of WT penetration is presented in [12]. Gathered grid frequency and generator output signals are examined to estimate the load inertia [12]. Calculations show load inertia being in the range of 0.1 to $1.1 \mathrm{~s}$ [12]. Bian et al. use historical data of grid frequency outage events to estimate the inertia demand side contribution [13]. Therefore, a power/frequency ratio is used because real power output had to be used instead of the total capacity of generators [13]. Their research shows that the demand side contributes an average inertia constant of $1.75 \mathrm{~s}$ for the UK power system, represents $20 \%$ of the total system inertia [13].

Early in the morning on 9 January 2019 a blackout occurred in the German city named Flensburg. Only connected via one transmission line to Denmark, a permanent short circuit in that exact power line occurred. In the cause of de-energizing the fault location Flensburg was permanently disconnected from the Continental European power system and had to be operated as an island power system by the Stadtwerke Flensburg, the local energy supplier. Facing a major power imbalance, the local power supplier was not able to maintain power system stability and a necessary cascade-like load shedding resulted in a almost full blackout. Intensive collaboration with the Stadtwerke Flensburg allowed for a detailed research on this event by the Wind Energy Technology Institute of the Flensburg University of Applied Sciences. Part of this research examined the load inertia contribution of different consumer groups i.e., private households, retail businesses, trade and commerce as well as industry.

The second section of the paper at hand describes the basics about power system stability and the influence of power system inertia. Subsequently, the blackout event that occurred on 9 January 
2019 is described followed by the categorisation of power consumers. The third section describes how the inertia contribution is calculated and the results of these calculations are presented, followed by a discussion of the results. The last section summarises the findings.

\section{Methodology}

As introduced in the previous section, only a few publications determine the amount of inertia supplied by power consumers. The work at hand aims to extends the state of knowledge. For this reason, different power consumer groups are defined and its inertia contribution is determined. Therefore, the basics about power system stability and power system inertia are explained. The calculations of this work are based on a blackout incident which occurred in a small power system of which detailed information is available. The categorisation of power consumer groups are described at last.

\subsection{Power System Inertia}

Power generation and power consumption (In this work, power consumption includes grid losses.)have to be balanced constantly in AC power systems [17]. In liberalised markets, power balance is achieved via power trading processes prior to the actual unit commitment [18]. In real time, when power units are deployed, power balance is achieved via an active power control commonly referred to as load-frequency control [17]. An imbalance in power generation and power demand is reflected throughout the power system by a change in the grid frequency, $f_{\text {grid }}$ [17]. Hence, the grid frequency is the indicator for power balance [17]. It is directly related to all rotating masses that are synchronously connected to the power system [17].

For power system stability in general and especially for load-frequency control, power system inertia is vital. Units providing active power control are not able to adapt their power output instantaneously based on the power systems needs [17]. Adapted power output is fed into the grid with a certain time delay [17]. In the event of a power imbalance, synchronously connected rotating masses start accelerating or decelerating [2]. The speed with which the grid frequency changes, known as the Rate of Change of Frequency (ROCOF), $\delta f / \delta t$, is thereby reduced [2]. For instance: if power generation exceeds power consumption, the speed of the rotating masses increases and power taken from the power system is stored in the rotational motion in the form of kinetic energy [2]. If power consumption exceeds power generation the process works vice versa [2]. Equation (1) demonstrates the relationship

$$
\frac{\delta \omega}{\delta t}=\frac{T_{\text {gen }}-T_{\text {load }}}{J_{\text {sys }}}
$$

where $T_{\text {gen }}$ is the accumulated power generation torque, $T_{\text {load }}$ is the accumulated power consumption torque and $J_{s y s}$ the aggregated mass moment of inertia of all directly connected rotating machines referred to as power system inertia [17]. $\delta \omega / \delta t$ is the change of rotational speed of the synchronously connected machines [17]. Equation (2) explains the relationship between the stored kinetic energy, $E_{k i n}$ the moment of inertia of a synchronous machine, $J$, and the rotational speed of the rotating machine, $\omega$.

$$
E_{k i n}=\frac{1}{2} J \omega^{2}
$$

The stored kinetic energy in the rotation of a synchronous generator, $E_{k i n, g e n}$, is often expressed proportional to the machines power rating, $S_{\text {gen }}[2,17]$. This is called the inertia constant of the machine, $H_{\text {gen }}[2,17]$. It is a theoretical value expressing the duration in seconds the nominal power of the synchronous generator can solely be provided by the stored kinetic energy until the rotational speed decreases to zero [2,17]. The following equation expresses the relationship [2,17].

$$
H_{\text {gen }}=\frac{E_{k i n, g e n}}{S_{g e n}}=\frac{J_{g e n} \cdot \omega_{0}^{2}}{2 S_{g e n}}
$$


$S_{g e n}$ ist the rated power of the synchronous generator [2]. Typical values for the inertia constant of power generation units are between 2 to $10 \mathrm{~s}$ depending on the type of machine [17].

The overall power system inertia, $H_{\text {sys }}$, is calculated as follows [2]

$$
H_{s y s}=\frac{\sum H_{g e n, i} \cdot S_{g e n, i}}{\sum S_{g e n}}
$$

were $H_{g e n, i}$ is the inertia constant of the single generator, $S_{g e n, i}$ the apparent power of the generator and $S_{g e n}$ the total apparent power of the generators [2]. Equation (4) neglects the inertia provided by power consumers [2].

Due to the energy transition movement, fossil fuel driven power plants are replaced by RES, especially with a large share of WT and PV [6]. Most of these conventional power plants are equipped with synchronous generators [2]. State of the art WT and PV are connected to the power system via frequency converters [6]. Hence, even if a rotating mass exists, such as in the case of WT, the stored kinetic energy is hidden behind the converter for the grid [9]. However, some RES such as WT or energy storage systems connected via grid frequency converters are able to emulate the behaviour of a synchronous machine in the event of a power imbalance [8-11].

\subsection{Flensburg Blackout}

Early in the morning on 9 January 2019 an almost full blackout occurred in the city of Flensburg. In close proximity to the Danish boarder, Flensburg is a city with around 90,000 inhabitants. The local power supplier is the Stadtwerke Flensburg, with around 55,000 connected customers [19]. Prior to the events, approximately $62 \mathrm{MW}$ power was consumed locally and $47 \mathrm{MW}$ power exported to Denmark (see Figure 1). Flensburg was connected to Denmark via a $150 \mathrm{kV}$ transmission line. There was one phase angle regulating transformer (quadrature booster) connecting Flensburg to the surrounding German power system. At the time of the event no power was transferred through this connection.

At 06:18 a short circuit occurred in the $150 \mathrm{kV}$ transmission line to Denmark. The short circuit resulted in a disconnection of the transmission line. At the same time, the quadrature booster was disconnected by its protection relay (see Ev1 in Figure 1). Therefore, the power system of Flensburg became a grid island. The islanding operation, i.e., the inability to export power, lead to excess power and hence, an increase of $f_{\text {grid }}$. Consequently, the gas turbine part of the combined gas and steam turbine experienced an emergency shut down of the Generator 12 (see Ev1 in Figure 2). Following the event, the power consumption in the supply area increased and with now too little power generation capacity the grid frequency decreased (Figures 1 and 3). Stadtwerke Flensburg attempted to stabilise the grid frequency conducting load sheddings: 4.06 MW at 06:30 (Ev2 in Figures 1 and 3) and 3.8 MW at 06:38 (Ev3 in Figures 1 and 3). As normal for this time of the day, the load in the city increased. Consequently these load sheddings were not sufficient and the grid frequency decreased further to below $48.0 \mathrm{~Hz}$ (Ev4 in Figure 3). Another 4.38 MW of load were disconnected manually at 07:00 (Ev4 in Figure 1).

A synchronisation with the Danish power system using two $60 \mathrm{kV}$ backup lines was not possible due to large differences between the grid frequency in Flensburg and the grid frequency of the Danish power system, i.e., the power system of Continental Europe. Power consumption further increased (Figure 1) and the grid frequency did not stabilise (Figure 3). At 07:15:20 a large series of actions were taken to re-establish power system stability. Within 11 minutes several districts were disconnected in five steps (see Table 1 Ev5 to Ev9 and Figures 1 and 3 Ev5 to Ev9). Overall, 43.19 MW had to be disconnected. At 07:18:54 (see Table 1 Ev8) a second coal fired steam turbine (Generator 7) lost balance and as a result automatically disconnected from the power system (see Figure 2). At last, the Transformer Station (TS) "TS-HKW" remained connected as the last transformer station. 


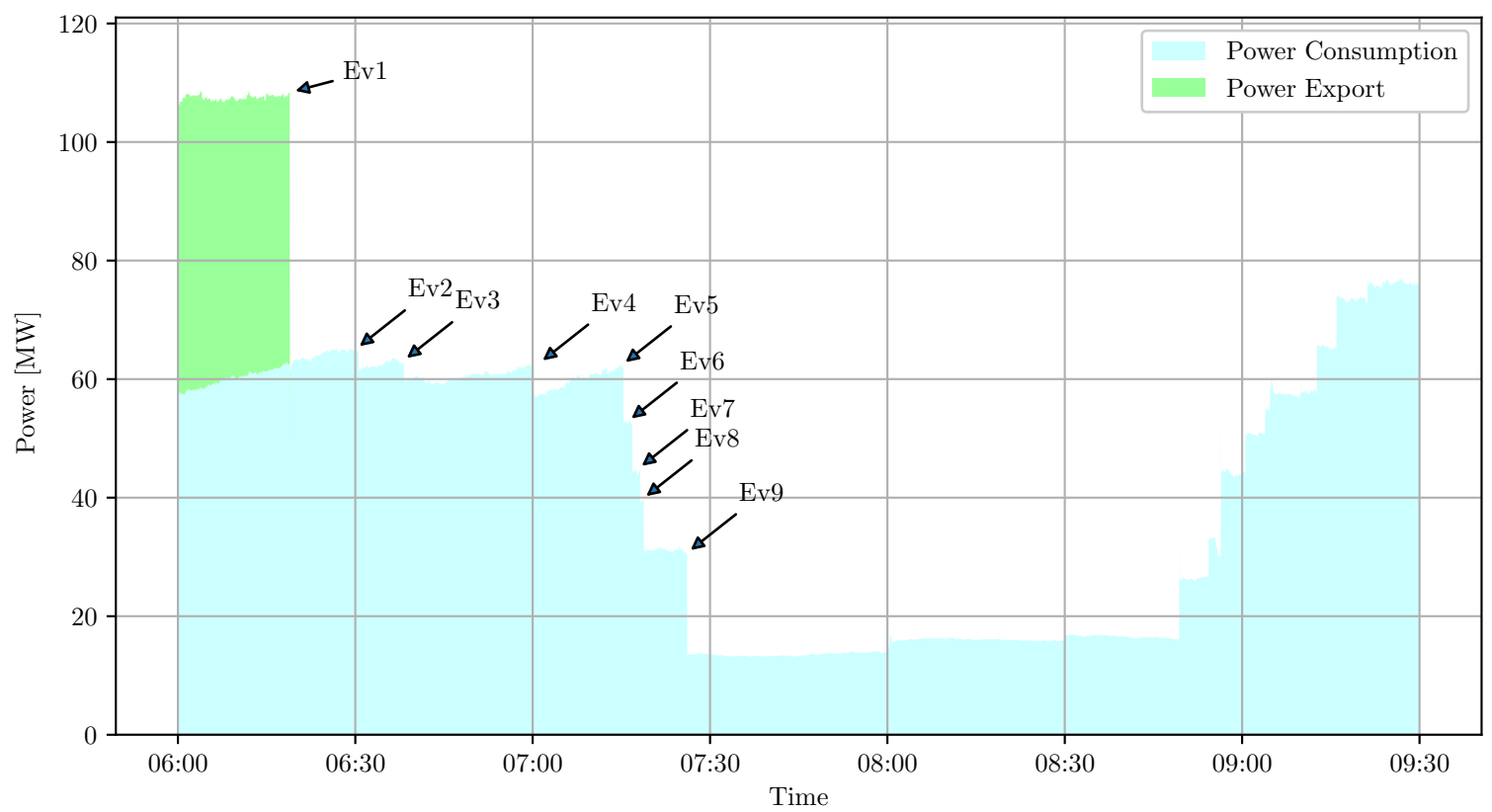

Figure 1. Illustration of the consumed power in Flensburg and the power exported to Denmark before the occurrence of the short circuit event. The arrows indicate the beginning of the events, i.e., the disconnection of generators or loads.

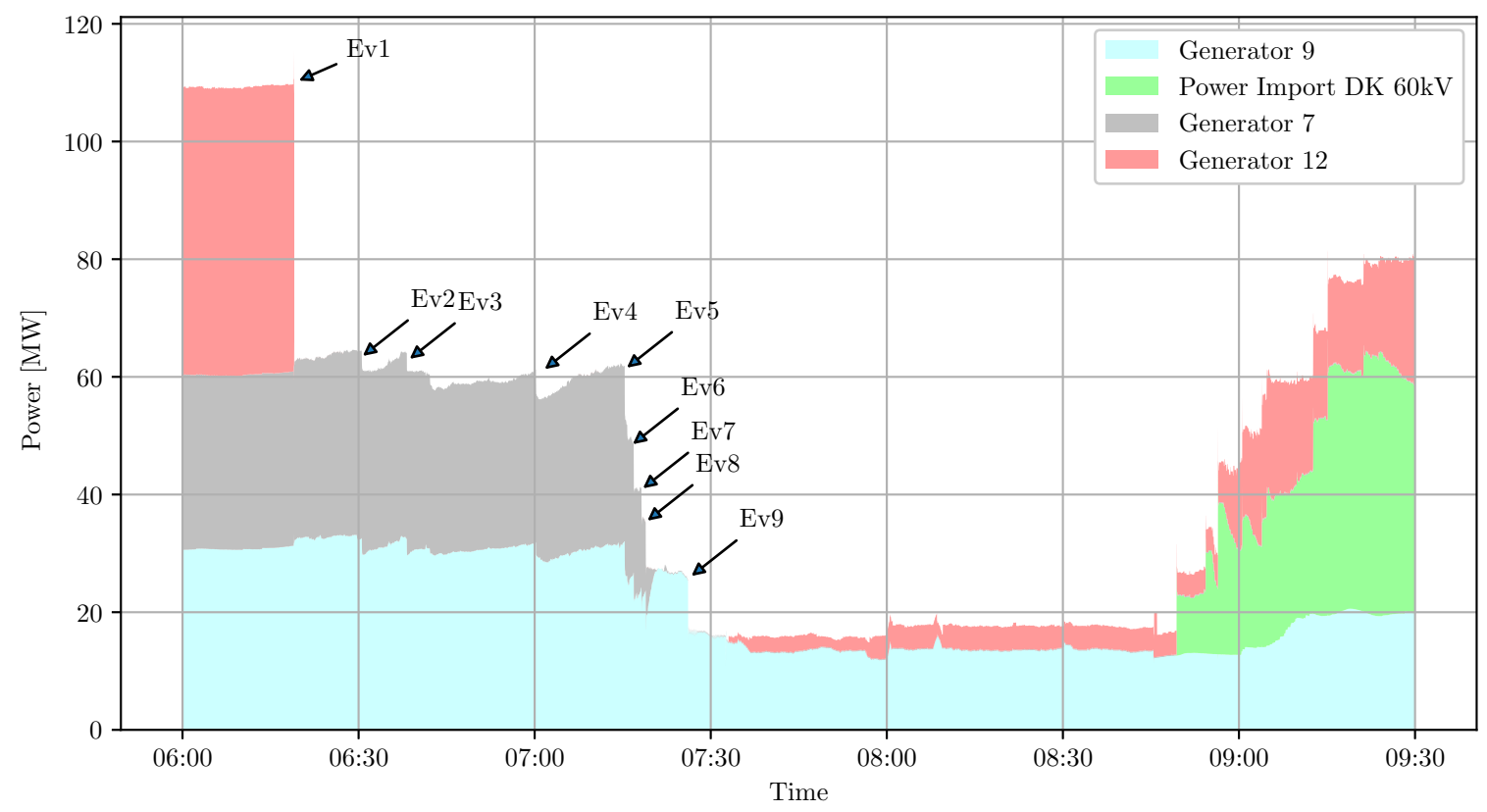

Figure 2. Illustration of the generated power by the local power supplier and the power imported from Denmark after synchronisation with the Danish power system. The arrows indicate the beginning of the events, i.e., the disconnection of generators or loads.

At 08:50 the Stadtwerke Flensburg were able to restore synchronisation with the Danish power system and power from Denmark was imported via the two $60 \mathrm{kV}$ backup lines. Stepwise, consumers were reconnected to the power system. At 09:15 most of the city was back online. Figure 4 shows the location of all transformer station in Flensburg and Figure 5 shows a schematic representation of the power system in Flensburg. 


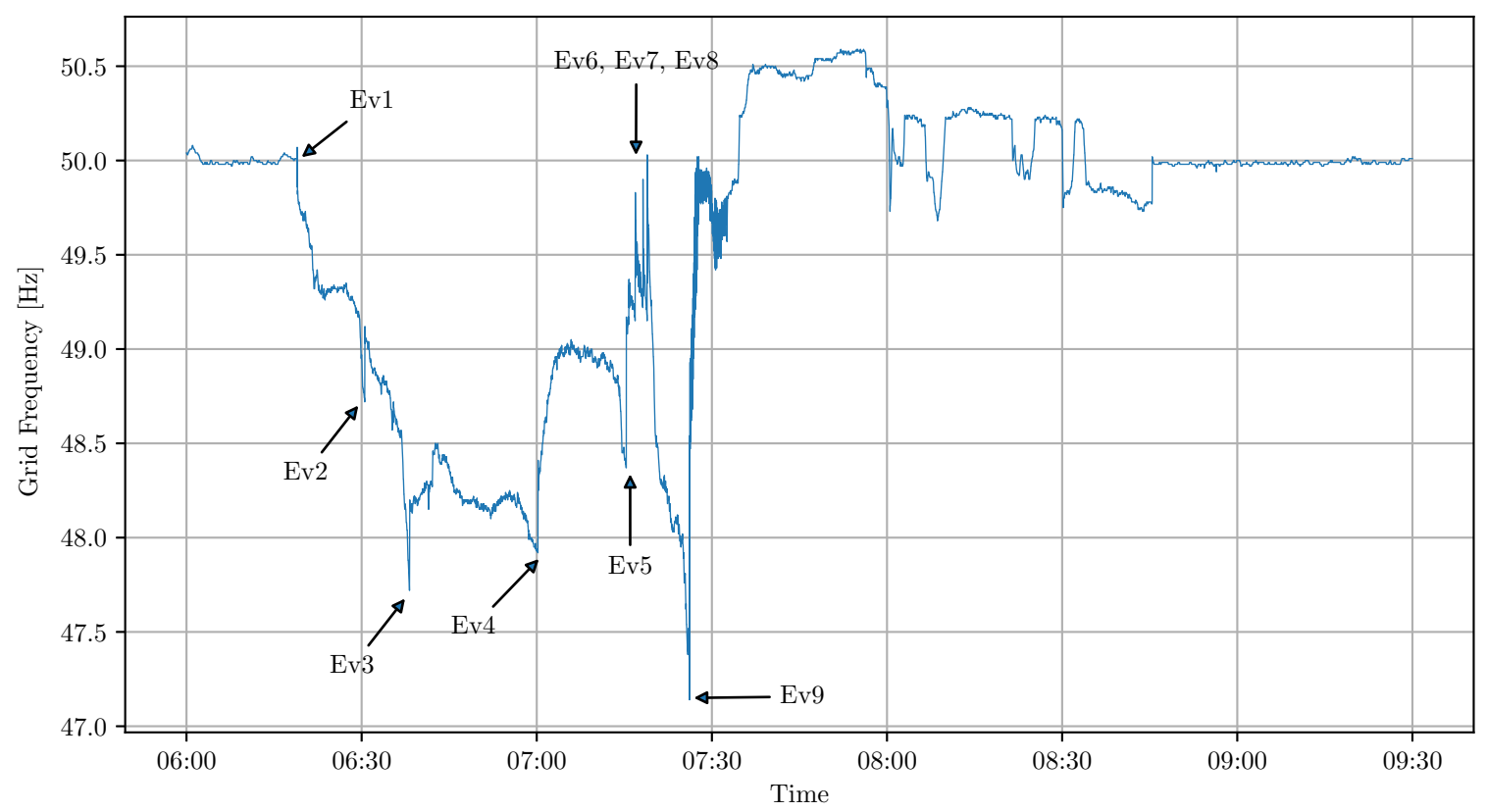

Figure 3. Illustration of the grid frequency during the blackout event. The arrows indicate the events.

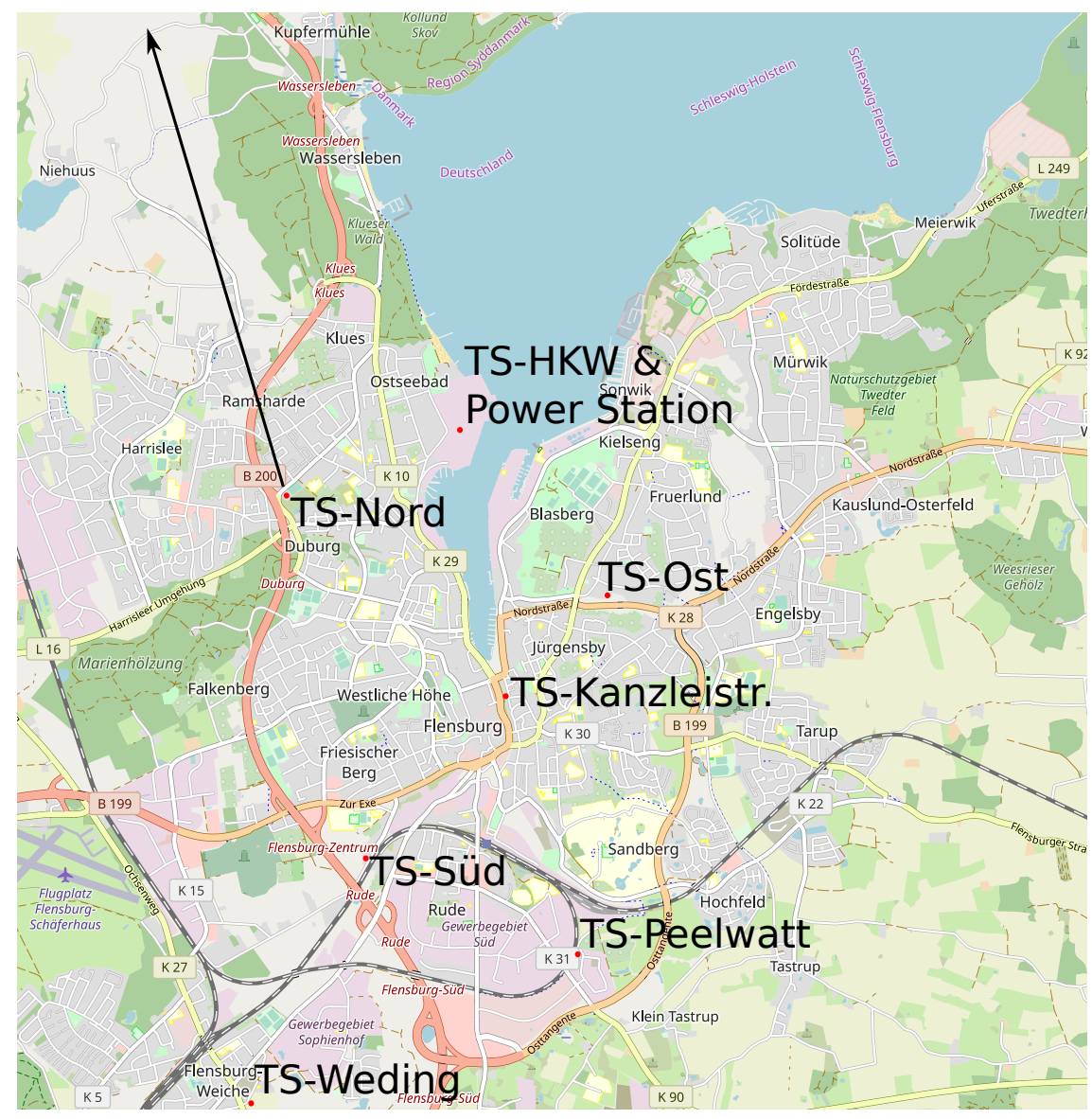

Figure 4. Map of Flensburg. Depicted by red dots are the locations of transformer stations and the power station [20]. (C) OpenStreetMap contributors. 
Table 1. Tabular list of the events. The list includes the initial short circuit event and the following load disconnection. For a more detailed description of the events see Section 2.2.

\begin{tabular}{lrlllll}
\hline ID & Time & Location of Event & Description of Event & $\boldsymbol{\Delta} \boldsymbol{P}[\mathbf{M W}]$ & $f_{\text {grid }}[\mathbf{H z}]$ & $\mathbf{R O C O F}[\mathbf{H z} / \mathbf{s}]$ \\
\hline Ev1 & $06: 18: 54$ & Grid line DK & Short circuit & 48.58 & 49.82 & 0.591 \\
Ev2 & $06: 30: 32$ & TS-Ost & Stepwise load shedding & 4.06 & 49.12 & 0.3653 \\
Ev3 & $06: 38: 11$ & TS-Ost & Stepwise load shedding & 3.8 & 48.2 & 0.3695 \\
Ev4 & $07: 00: 09$ & TS-Ost & Full load shedding & 4.38 & 48.41 & 0.4391 \\
Ev5 & $07: 15: 19$ & TS-Karlstr. & Full load shedding & 7.9 & 49.17 & 0.782 \\
Ev6 & $07: 16: 49$ & TS-Peelwatt & Full load shedding & 9.45 & 48.83 & 0.9381 \\
Ev7 & $07: 18: 10$ & TS-Nord & Stepwise load shedding & 6.36 & 49.9 & 0.6425 \\
Ev8 & $07: 18: 54$ & TS-Nord & Stepwise load shedding & 9.24 & 49.93 & 0.9744 \\
Ev9 & $07: 25: 59$ & TS-Süd & Full load shedding & 10.24 & 48.54 & 2.18 \\
\hline
\end{tabular}

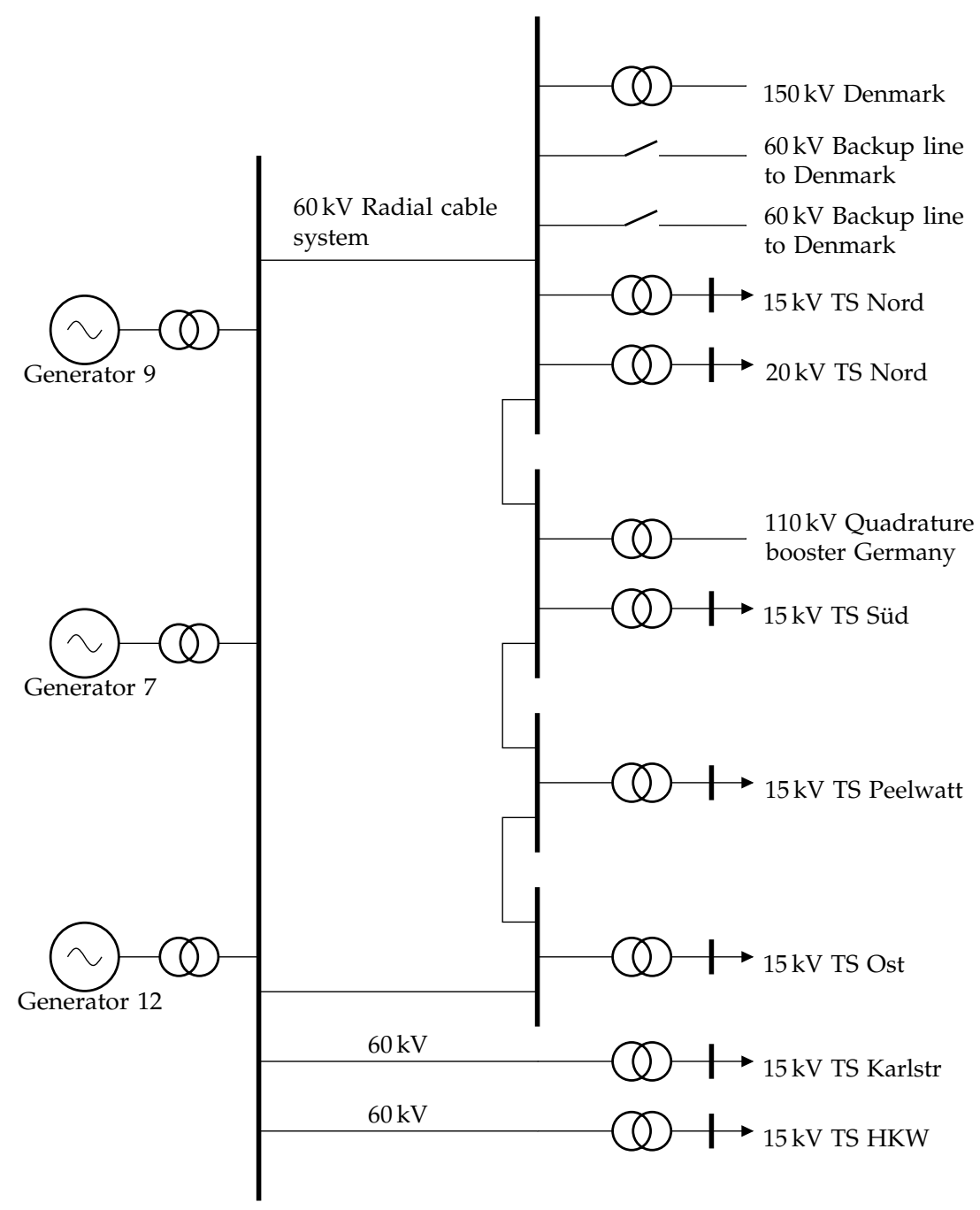

Figure 5. Schematic representation of the power system in Flensburg. The left part of the figure depicts the power generation side and the right part of the Figure depicts the power consumption side as well as the connection lines to the surrounding grid connection points

\subsection{Power Consumer Groups}

The literature review has shown that little is known about detailed inertia contribution coming from different groups of power consumers. Literature values for the average inertia constant of different power generators exist [17]. The same type of information is not available for inertia contribution of 
different power consumer groups. The Flensburg blackout event allows for more detailed research on this open research question. Therefore, power consumers are organised into groups.

To stabilise the grid frequency, the local power supplier disconnected single city districts automatically or manually. Each disconnected district is categorised based on the dominating type of consumers. Following the categorisation of power consumers by the German Association of Energy and Water Industries (Bundesverband der Energie- und Wasserwirtschaft (BDEW)) a similar approach to organise power consumers is applied in this work [21]. The categorisation by the BDEW contains groups such as private households, agricultural businesses and trade, commerce and industry businesses. As no agriculture businesses exist in Flensburg, this category is removed from the list. Instead, industrial and retail businesses are included.

The transformer stations "TS-Nord" and "TS-Ost" are to a large extent connected to private households. The transformer station "TS-Karlstr." is located in the centre of Flensburg. This area of Flensburg is characterised by retail businesses. The transformer stations "TS-Peelwatt" and "TS-Süd" in the southern part of Flensburg are characterised by mixture of trade and commerce businesses as well as industry businesses. The transformer station "TS-Weding" is the point where the quadrature booster connects to the $110 \mathrm{kV}$ transmission level in Germany. Hence, no category is assigned to this transformer station. The remaining transformer station "TS-HKW" is connected to an industry dominated district. Table 2 sums up the consumer categorisation

Table 2. List of transformer stations assigned consumer category.

\begin{tabular}{ll}
\hline Transformer Station & Category \\
\hline TS-Nord & Private households \\
TS-Ost & Private households \\
TS-Karlstr. & Retail businesses \\
TS-Peelwatt & Trade, commerce and industry businesses \\
TS-Süd & Trade, commerce and industry businesses \\
TS-HKW & Industry \\
TS-Weding & $(-)$ \\
\hline
\end{tabular}

\subsection{Calculations and Results}

The following section explains how the inertia contribution from power consumers is calculated and presents the results. The methodology to calculate the total inertia contribution from power consumers coincide with literature already presented in the introduction [12,13].

Extending Equation (1) by $P=T \cdot \omega$ and $\omega=2 \pi f$ leads to

$$
\frac{\delta f}{\delta t}=\frac{\Delta P}{4 \pi^{2} \cdot f \cdot J}
$$

where $\delta f / \delta t$ is the ROCOF and $\Delta P$ the imbalance between power generation and power consumption. Solving Equation (5) for $J_{s y s}$ results in

$$
J_{\text {sys }}=\frac{\Delta P}{4 \pi^{2} \cdot f_{\text {grid }} \cdot R O C O F}
$$

Taking $\triangle P, f_{\text {grid }}$ and the ROCOF as listed in Table 1 the amount of power system inertia, $J_{s y s}$, directly after the occurrence of the event can be calculated. Subtracting the overall sum of the synchronously connected generators, $\sum J_{g e n, i}$ (see Figure 2 and Table 3 ) leads to the overall amount of inertia supplied from power consumers, Jload.

$$
J_{\text {load }}=J_{\text {sys }}-\sum J_{\text {gen }, i}
$$

It is assumed that the amount of inertia supplied from power consumers, $J_{\text {load }}$, does not change significantly in the time between two events, i.e., the disconnection of city districts. Hence, 
by subtracting the amount of inertia after the event, $J_{l o a d, n}$, from the amount of inertia before the event, $J_{\text {load }, n-1}$, the moment of inertia from the previously disconnected district, $J_{\text {load, district }, n}$, can be calculated. It has to be mentioned here that this methodology is applicable because the inertia contribution from the generators is known and remains constant, unless stated otherwise. The following equation clarifies the relationship.

$$
J_{\text {load, }, \text { district }, n}=J_{\text {load }, n-1}-J_{\text {load }, n}
$$

Figure 6 illustrates the before explained methodology to calculate amount of inertia per district, $J_{\text {load,district }, n}$. Table 4 sums up the calculated results for the amount of power system inertia, $J_{\text {sys }}$, the overall amount of inertia from the consumer side, $J_{l o a d}$, as well as the amount of inertia per district, $J_{\text {load, district, } n \text {. }}$

Taking Equation (2), the amount of stored kinetic energy in the rotational motion of the connected machines at rated speed can be calculated. Therefore, the rated rotational speed, $\omega_{0}$, i.e., rated frequency, $f_{0}$, of $50 \mathrm{~Hz}$ is used [17]. This method coincides with [13]. Bian et al. used a power/frequency ratio to correct calculations. This is because real power output data is used for the calculations instead of total capacity of each generator [13]. As the Stadtwerke Flensburg provieded detailed information about the connected generators, an adjustment of the calculations is not necessary. The results are listed in Table 5.

It is state of the art to describe the robustness of a power system with the inertia constant, $H_{s y s}$ [2]. The inertia constant is also useful to compare either single synchronously connected generators $\left(H_{\text {gen }, i}\right)$ or power systems $\left(H_{s y s}\right)$. However, as stated above, $H_{s y s}$ neglects the inertia provided by power consumers [2]. Hence, including the inertia provided by power consumers, Equation (4) has to be extended as follows

$$
H_{\text {sys }}=\frac{\sum H_{\text {gen }, i} \cdot S_{\text {gen }, i}}{\sum S_{\text {gen }}}+\frac{\sum H_{\text {load }, i} \cdot S_{\text {load }, i}}{\sum S_{\text {load }}}
$$

were the first summand accounts for the total inertia constant of the synchronously connected generators and the second summand for the total inertia constant of the synchronously connected loads. Since, the apparent power of the synchronous loads is unknown, two different approaches are applied in this work to calculate the inertia constant from loads. The first approach is presented by Tavakoli et al. where the load inertia constant is based on the all system demand, $H_{\text {load,P_dem }}$ [12].

$$
H_{\text {load, }, P_{-} \text {dem }}=\frac{E_{k i n, l o a d}}{P_{\text {dem }}}
$$

The inertia constant per district, $H_{\text {load, } P \_ \text {dem,district }}$, is calculated according to Equation (10) using the stored kinetic energy of the district, $E_{k i n, \text { district }}$, and the power demand of the disconnected district, $P_{P_{-} \text {dem,district }}$. The second approach uses the sum of the apparent power of all connected synchronous generators to calculate the load inertia constant, $H_{\text {load,S_gen }}$.

$$
H_{\text {load,S_gen }}=\frac{E_{\text {kin,load }}}{S_{\text {gen }}}
$$

To calculate the inertia constant per district, $H_{\text {load,S_gen,district }}$, for the second method according to Equation (11) the stored kinetic energy of the district, $E_{k i n, \text { district, }}$ and the apparent power of the generators, $S_{\text {gen }}$, has to be used. By applying this approach, the actual inertia contribution of the power consumers to the overall power system inertia is directly visible. Table 6 sums up the results. 


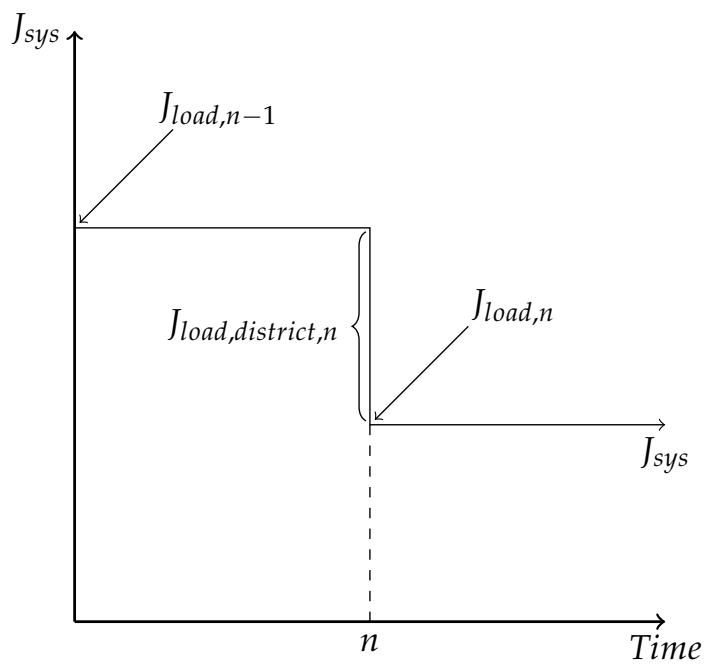

Figure 6. Illustration of the methodology to calculate the amount of inertia supplied by single districts which have been disconnected from the power system. Subtracting $J_{\text {load }, n}$ from $J_{\text {load, } n-1}$ results in Jload, district, $n$.

Table 3. Relevant combined turbine and generator specifications. Specifications of Generator 12 are not listed, as data is unknown and not necessary for the calculations conducted here.

\begin{tabular}{lrrrr}
\hline Name & $S_{\text {gen }}[\mathrm{MVA}]$ & $J_{\text {gen }}\left[\mathbf{k g m}^{2}\right]$ & $\boldsymbol{H}_{\text {gen }}[\mathbf{s}]$ & No. Poles \\
\hline Generator 9 & 41.6 & 2222.71 & 2.63 & 2 \\
Generator 7 & 44.9 & 2292.95 & 2.52 & 2 \\
\hline
\end{tabular}

Table 4. Tabular list of calculated moment of inertia $J_{\text {sys }}, J_{\text {load }}$ and $J_{\text {load,district }}$. The colour background in the column Disconnected district indicates the allocation as listed in Table 2

\begin{tabular}{lllll}
\hline ID & $J_{\text {sys }}\left[\mathbf{k g m}^{2}\right]$ & $J_{\text {load }}\left[\mathbf{k g m}^{2}\right]$ & $J_{\text {load,district }}\left[\mathbf{k g m}^{2}\right]$ & Disconnected District \\
\hline Ev1 & - & - & - & - \\
Ev2 & 5731.37 & 1215.70 & - & TS-Ost \\
Ev3 & 5404.59 & 888.91 & 326.78 & TS-Ost \\
Ev4 & 5219.34 & 703.67 & 185.24 & TS-Ost \\
Ev5 & 5204.28 & 688.61 & 15.07 & TS-Karlstr \\
Ev6 & 5120.73 & 605.06 & 83.54 & TS-Peelwatt \\
Ev7 & 5024.86 & 509.19 & 95.88 & TS-Nord \\
Ev8 & 4810.76 & 295.09 & 214.10 & TS-Nord \\
Ev9 & 2451.23 & 158.28 & 136.81 & TS-Süd \\
- & - & - & 158.28 & TS-HKW \\
\hline
\end{tabular}

Table 5. Tabular list of calculated stored kinetic energy. The colour background in the column Disconnected district indicates the allocation as listed in Table 2

\begin{tabular}{lllll}
\hline ID & $E_{\text {kin,sys }}[\mathrm{MWs}]$ & $E_{\text {kin,load }}$ [MWs] & $\boldsymbol{E}_{\text {kin,load,district }}$ [MWs] & Disconnected District \\
\hline Ev1 & - & - & - & \\
Ev2 & 282.83 & 59.99 & - & TS-Ost \\
Ev3 & 266.71 & 43.87 & 16.13 & TS-Ost \\
Ev4 & 257.56 & 34.72 & 9.14 & TS-Ost \\
Ev5 & 256.82 & 33,98 & 0.74 & TS-Karlstr \\
Ev6 & 252.70 & 29.86 & 4.12 & TS-Peelwatt \\
Ev7 & 247.97 & 25.13 & 4.73 & TS-Nord \\
Ev8 & 237.40 & 14.56 & 10.57 & TS-Nord \\
Ev9 & 120.96 & 7.81 & 6.75 & TS-Süd \\
- & - & - & 7.81 & TS-HKW \\
\hline
\end{tabular}


Table 6. Tabular list of calculated inertia constants. The colour background in the column Disconnected district indicates the allocation as listed in Table 2, The upper part of the table shows the power system inertia constant and the load inertia constants. The lower part shows the load inertia constants per disconnected district

\begin{tabular}{lllllll}
\hline ID & $\boldsymbol{H}_{\text {sys }}[\mathbf{s}]$ & $\boldsymbol{H}_{\text {load,P_dem }}[\mathbf{s}]$ & $\boldsymbol{H}_{\text {load,__gen }}[\mathbf{s}]$ & $\boldsymbol{H}_{\text {load,P_dem,district }}[\mathbf{s}]$ & $\boldsymbol{H}_{\text {load,S_gen,district }}[\mathbf{s}]$ & Disconnected District \\
\hline Ev1 & - & - & - & - & - & - \\
Ev2 & 3.27 & 0.99 & 0.69 & - & - & TS-Ost \\
Ev3 & 3.09 & 0.73 & 0.51 & 4.24 & 0.19 & TS-Ost \\
Ev4 & 2.98 & 0.61 & 0.40 & 2.09 & 0.11 & TS-Ost \\
Ev5 & 2.97 & 0.63 & 0.39 & 0.09 & 0.01 & TS-Karlstr \\
Ev6 & 2.92 & 0.75 & 0.35 & 0.44 & 0.05 & TS-Peelwatt \\
Ev7 & 2.87 & 0.73 & 0.29 & 0.74 & 0.05 & TS-Nord \\
Ev8 & 2.75 & 0.56 & 0.17 & 1.14 & 0.12 & TS-Nord \\
Ev9 & 2.70 & 0.51 & 0.17 & 0.66 & 0.15 & TS-Süd \\
- & - & - & 0.51 & 0.17 & - & TS-HKW \\
\hline
\end{tabular}

\section{Discussion of Results}

The calculations of the overall amount of power system inertia, the amount of inertia provided by the power consumer side, as well as the amount of inertia provided by disconnected districts, are shown in the previous section. The first calculated power inertia constant directly after the disconnection of the first district (Ev2) results in $3.27 \mathrm{~s}$. The result is narrowly beneath the range of power inertia constants (3.5-7.5 s) presented by Chassin et al. in [15]. There are three reasons for that shortfall:

1. Due to the short circuit in the transmission line to Denmark at 06:18:54 a large gas and steam turbine (Generator 12 in Figures 2 and 5) of the Stadtwerke Flensburg got disconnected from the power system. Considering that this gas and steam turbine set up provides a large moment of inertia, the overall power system inertia constant for the Flensburg power area would be much higher and most likely in the range of 3.5-7.5 s.

2. The researched power system is rather small with only little power generation sources and little industry. Hence, little synchronously rotating loads. Therefore it is likely that the inertia constant of the Flensburg power area is naturally at the lower end of the 3.5-7.5 s range.

3. Due to the emergency situation the available generators operated at their maximum power output. In normal power system operation a larger number of power plants operate at lower operating points to secure redundancy. Hence, considering Equation (3), in this emergency situation the inertia constant provided by the generators is naturally low.

Overall, 282.83 MWs of kinetic energy were stored in the rotation movement of all synchronously connecting machines after the disconnection of the first district on Flensburg. $21.21 \%$ (59.99 MWs) were stored on the power consumer side. This result coincide with existing literature [13]. Based on the calculation method, the load inertia constant results in $H_{\text {load,P_dem }}=0.99 \mathrm{~s}$ and $H_{\text {load,S_gen }}=0.69 \mathrm{~s}$. Comparing $H_{l o a d, P \_d e m}$ with the findings of Tavakoli et al. where the load inertia constant ranges from 0.1-1.1 s, again, the result coincide with existing literature [12].

The load inertia constant for $H_{\text {load,P_dem,district }}$ ranges from 0.09 up to $4.24 \mathrm{~s}$ and for

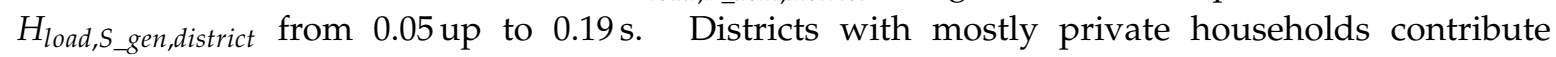
with a inertia constant from 0.74 to $4.24 \mathrm{~s}$ for the calculation method of $H_{\text {load, } P_{-} \text {dem,district }}$. Table 7 summarises the results and Figure 7 illustrates the before presented results using a bar chart plot. In addition, with a range of 0.05 to $0.19 \mathrm{~s}$ for the method resulting in $H_{\text {load,S_gen,district }}$. The high inertia constant for the category of private households is most likely explained with the manual disconnection of loads during the first part of the blackout event. The first three loads were disconnected manually from the power system. Even though connected to a district dominated by private households, large consumers with higher inertia contribution were disconnected first. For instance, two larger military areas are connected to the transformer station "TS-Ost". Rotating 
loads are likely applied there. The very low value of the retail business category can be explained by the early morning time in which the incident occurred. Only a few retail businesses were opened during that time. Hence, only little inertia was contributed by this customer group. The third category, trade, commerce businesses and industry, ranges from 0.44 to $0.66 \mathrm{~s}$ for $H_{\text {load, }} P_{-}$dem,district or from 0.05 to $0.15 \mathrm{~s}$

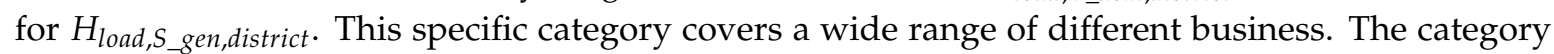
industry contributes a load inertia constant of $H_{\text {load,P_dem,district }}=0.51 \mathrm{~s}$ or $H_{\text {load,S_gen,district }}=0.17 \mathrm{~s}$.

Table 7. Summary of the results per category

\begin{tabular}{lll}
\hline Category & $\boldsymbol{H}_{\text {load,P_dem,district }}[\mathrm{s}]$ & $\boldsymbol{H}_{\text {load,S_gen,district }}[\mathrm{s}]$ \\
\hline Private households & $0.74-4.24$ & $0.05-0.19$ \\
Retail businesses & 0.09 & 0.01 \\
Trade, commerce businesses and industry & $0.44-0.66$ & $0.05-0.15$ \\
Industry & 0.51 & 0.17 \\
\hline
\end{tabular}

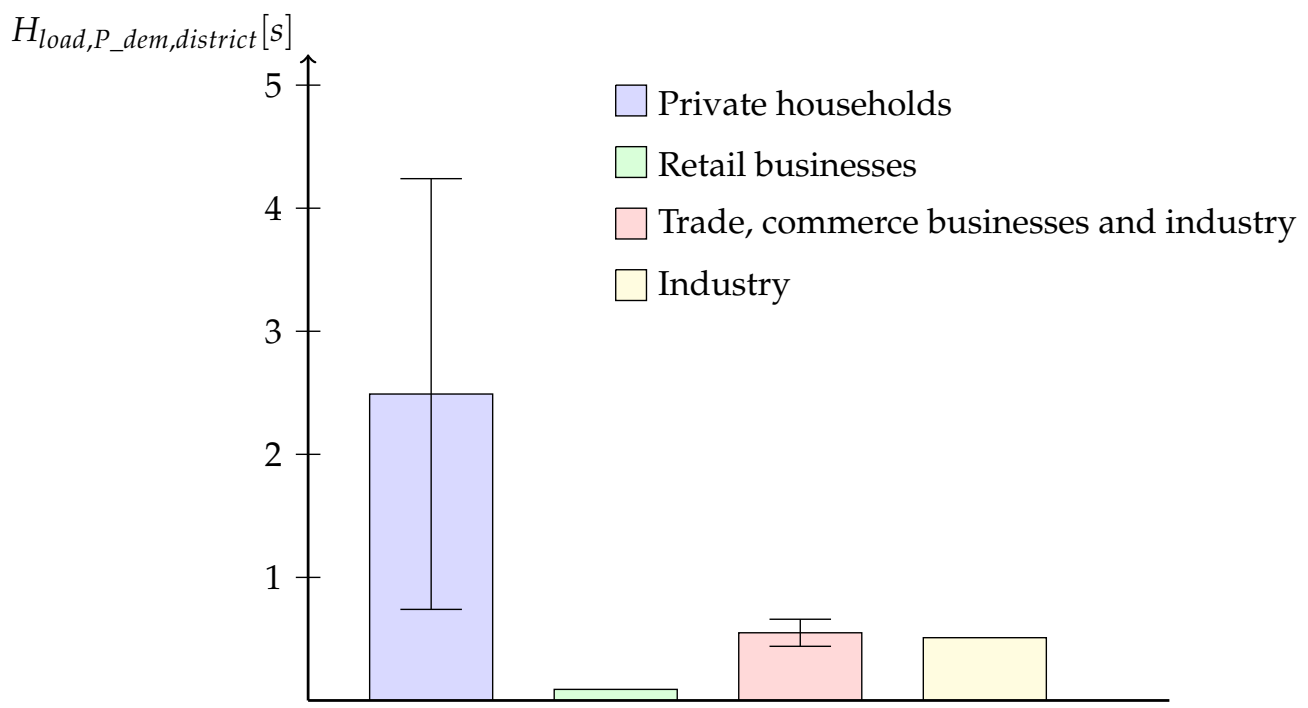

Figure 7. Illustration of the calculated results of $H_{\text {load, } P_{-} \text {dem,district }}[s]$. Each depicted bar shows the inertia provided by the particular consumer category. The bars for the categories Private Households and Trade, commerce businesses and industry show a range of the inertia constant. The colored bar indicates the average inertia constant and the vertical line in the middle of the two bars indicate the range of results.

\section{Conclusions}

The paper at hand sums up the importance of power system inertia for power system stability and determines the inertia contribution from different power consumer groups. Due to decarbonisation efforts in power systems, synchronously connected generators of conventional power plants get replaced by RES, mostly WT and PV. Hence, power system inertia is declining in power systems. To sustain controllability of future power systems, synthetic inertia has to be provided by various sources. As an inertial response is provided by synchronously rotating masses in general, power consumers contribute to the overall power system inertia too. To use synthetic inertia most efficiently and cost effective, a precise knowledge about the inertia provided by power consumers is necessary.

A short circuit in a transmission line to Denmark resulted in a decoupling of the Flensburg power system and a cascade-like disconnection of districts in order to re-establish power balance. This incident allows for a detailed research of the inertia contribution of different power consumer groups. For the sake of this research, four consumer categories are introduced: private households, retail businesses, trade, commerce businesses, and industry as well as industry alone.

The overall kinetic energy provided from power consumers contributes $21.21 \%$ to the overall stored kinetic energy. Two methods are applied to calculate the inertia constant from power consumers. 
The first method uses the power demand as a basis and the second method applies the overall apparent power by the connected synchronous generators. Therefore, the inertia contribution from a specific customer group is clearly visible. The inertia contribution per consumer category ranges from $H_{\text {load, } P_{-} \text {dem,district }}=0.09 \mathrm{~s}$ or rather $H_{\text {load,S_gen,district }}=0.01 \mathrm{~s}$ for the retail business category up to $H_{\text {load,P_dem,district }}=4.24 \mathrm{~s}$ or rather $H_{\text {load,S_gen,district }}=0.19 \mathrm{~s}$ in the private household category. There is a large inertia contribution range in single categories. Especially in the private household category, where the $H_{\text {load, }, P_{-} \text {dem,district }}$ range is from 0.74 to $4.24 \mathrm{~s}$ or $H_{\text {load,S_gen,district }}$ range from 0.05 to $0.19 \mathrm{~s}$.

Finally, the blackout event in Flensburg on 9 January 2019 provides valuable insights about the inertia contribution from power consumers. The results allow for a likewise comparison of the inertia constant of power consumers similar to already existing values for power generation units [17]. Additionally, the share of the inertia contribution from different power consumer groups is determined and can be used to assess future application of synthetic inertia.

Author Contributions: H.T. performed the research and wrote the paper. C.J. reviewed the methodology and the text and contributed with valuable discussion and supervision. All authors have read and agreed to the published version of the manuscript.

Funding: The authors acknowledge financial support by Land Schleswig-Holstein within the funding programme Open Access-Publikationsfonds.

Acknowledgments: The authors acknowledge the contribution of the Stadtwerke Flensburg GmbH by providing various datasets from the blackout event and technical information. Map data copyrighted OpenStreetMap contributors and available from https:/ / www.openstreetmap.org.

Conflicts of Interest: The authors declare no conflict of interest.

\section{Abbreviations}

The following abbreviations are used in this manuscript:

PV Photovoltaic Systems

RES Renewable Energy Sources

ROCOF Rate of Change of Frequency

TS Transformer Station

WT Wind Turbines

\section{References}

1. UN. United Nations Framework Convention on Climate Change (UNFCCC). 7. d Paris Agreement. 2016. Available online: https:/ / treaties.un.org/doc/Treaties/2016/02/20160215\%2006-03\%20PM/Ch_XXVII-7d.pdf (accessed on 15 January 2020).

2. Tielens, P.; Hertem, D.V. The relevance of inertia in power systems. Renew. Sustain. Energy Rev. 2016, 55, 999-1009. [CrossRef]

3. Eurostat; European Statistical Office. Gross and Net Production of Electricity and Derived Heat by Type of Plant and Operator; Eurostat: Luxembourg, 2019.

4. Karampelas, P.; Ekonomou, L. Electricity Distribution: Intelligent Solutions for Electricity Transmission and Distribution Networks, 1st ed.; Springer Publishing Company: Berlin, Germany, 2016.

5. Fini, M.H.; Golshan, M.E.H. Determining optimal virtual inertia and frequency control parameters to preserve the frequency stability in islanded microgrids with high penetration of renewables. Electr. Power Syst. Res. 2018, 154, 13-22. [CrossRef]

6. Ulbig, A.; Borsche, T.S.; Andersson, G. Analyzing Rotational Inertia, Grid Topology and their Role for Power System Stability. IFAC-PapersOnLine 2015, 48, 541-547. [CrossRef]

7. Tamrakar, U.; Shrestha, D.; Maharjan, M.; Bhattarai, B.P.; Hansen, T.M.; Tonkoski, R. Virtual inertia: Current trends and future directions. Appl. Sci. 2017, 7, 654. [CrossRef]

8. Thiesen, H.; Jauch, C.; Gloe, A. Design of a System Substituting Today's Inherent Inertia in the European Continental Synchronous Area. Energies 2016, 9, 582. [CrossRef]

9. Gloe, A.; Jauch, C.; Craciun, B.; Winkelmann, J. Continuous provision of synthetic inertia with wind turbines: implications for the wind turbine and for the grid. IET Renew. Power Gener. 2019, 13, 668-675. [CrossRef] 
10. Wang, X.; Gao, W.; Yan, W.; Wang, J.; Muljadi, E.; Gevorgian, V.; Scholbrock, A. Evaluation of the inertial response of variable-speed wind turbines using advanced simulation. In Proceedings of the 2017 IEEE Power Energy Society General Meeting, Chicago, IL, USA, 16-20 July 2017; pp. 1-5. [CrossRef]

11. Li, Y.; Xu, Z.; Wong, K.P. Advanced Control Strategies of PMSG-Based Wind Turbines for System Inertia Support. IEEE Trans. Power Syst. 2017, 32, 3027-3037. [CrossRef]

12. Tavakoli, M.R.B.; Power, M.; Ruttledge, L.; Flynn, D. Load Inertia Estimation Using White and Grey-Box Estimators for Power Systems with High Wind Penetration. IFAC Proc. Vol. 2012, 45, 399-404. [CrossRef]

13. Bian, Y.; Wyman-Pain, H.; Li, F.; Bhakar, R.; Mishra, S.; Padhy, N.P. Demand Side Contributions for System Inertia in the GB Power System. IEEE Trans. Power Syst. 2018, 33, 3521-3530. [CrossRef]

14. Inoue, T.; Taniguchi, H.; Ikeguchi, Y.; Yoshida, K. Estimation of power system inertia constant and capacity of spinning-reserve support generators using measured frequency transients. IEEE Trans. Power Syst. 1997, 12, 136-143. [CrossRef]

15. Chassin, D.P.; Huang, Z.; Donnelly, M.K.; Hassler, C.; Ramirez, E.; Ray, C. Estimation of WECC system inertia using observed frequency transients. IEEE Trans. Power Syst. 2005, 20, 1190-1192. [CrossRef]

16. Wall, P.; Gonzalez-Longatt, F.; Terzija, V. Estimation of generator inertia available during a disturbance. In Proceedings of the 2012 IEEE Power and Energy Society General Meeting, San Diego, CA, USA, 22-26 July 2012; pp. 1-8. [CrossRef]

17. Kundur, P.; Balu, N.; Lauby, M. Power System Stability and Control; EPRI Power System Engineering Series; McGraw-Hill: New York, NY, USA, 1994.

18. Kirschen, D.; Strbac, G. Fundamentals of Power System Economics; Wiley: Hoboken, NJ, USA, 2004; Volume 1.

19. Stadtwerke Flensburg. Stadtwerke Flensburg-Über uns. 2019. Available online: https://www.stadtwerkeflensburg.de/unternehmen/ueber-uns / (accessed on 25 January 2019).

20. OpenStreetMap Contributors. Planet Dump. 2017. Available online: https://planet.osm.org (accessed on 15 January 2020).

21. Fünfgeld, C.; Tiedemann, R. Anwendung der Repräsentativen VDEW-Lastprofile Step-by-Step. 2000. Available online: https://www.bdew.de/media/documents/2000131_Anwendung-repraesentativen_ Lastprofile-Step-by-step.pdf (accessed on 15 January 2020).

(C) 2020 by the authors. Licensee MDPI, Basel, Switzerland. This article is an open access article distributed under the terms and conditions of the Creative Commons Attribution (CC BY) license (http://creativecommons.org/licenses/by/4.0/). 